\title{
PRODUÇÃO E QUALIDADE FISIOLÓGICA DE SEMENTES DE SOJA AVALIADAS NA SEMEADURA DE INVERNO
}

\author{
Carlos Alexandre Costa Crusciol1,3*; Edson Lazarini²; Cássio Luis Buzo²; Marco Eustáquio de \\ Sá ${ }^{2}$ \\ ${ }^{1}$ Depto. de Produção Vegetal, Setor Agricultura e Melhoramento Vegetal - UNESP/FCA, C.P. 237 - CEP:18603-970- \\ Botucatu, SP. \\ ${ }_{3}^{2}$ Depto. de Fitotecnia, Economia e Sociologia Rural - UNESP/FE, C.P. 31 - CEP: 15385-000 - Ilha Solteira, SP. \\ ${ }^{3}$ Bolsista CNPq. \\ *Autor correspondente <crusciol@fca.unesp.br>
}

RESUMO: O cultivo da soja fora da época convencional pode ser uma alternativa de rotação de cultura além de proporcionar sementes de melhor qualidade fisiológica, que podem ser utilizadas na semeadura da próxima safra diminuindo o período de armazenamento. O trabalho de pesquisa teve por objetivo avaliar o comportamento de sete cultivares de soja, em três densidades populacionais, quanto ao porte e altura de inserção da primeira vagem, assim como quanto à produção e qualidade fisiológica das sementes, semeadas no período de inverno, na região de Selvíria-MS. O delineamento experimental foi em blocos casualizados, com quatro repetições, dispostos em esquema fatorial $7 \times 3$. Os tratamentos constaram de sete cultivares (IAC-16, IAC-Foscarin 31, FT-2, IAC-17, IAC-8, Doko e FT-Cristalina) e três densidades de plantas (300, 400 e 500 mil plantas ha ${ }^{-1}$ ). O ciclo da soja foi reduzido no cultivo de inverno, principalmente nos cultivares considerados tardios. O fotoperíodo no cultivo de inverno reduziu o período entre o florescimento e a maturação. O cultivar IAC-8 foi o menos sensível ao fotoperíodo, possuindo maturação em época semelhante aos cultivares tardios, e apresentou as melhores características agronômicas para o cultivo no período de inverno. É aconselhável o aumento de densidade de semeadura quando do uso de cultivares precoces em cultivos de inverno. Não é aconselhável armazenar sementes em condições ambientes, principalmente com valores de germinação próximo ao limite inferior desejável (80\%).

Palavras-chave: densidade populacional, cultivares, altura da primeira vagem, armazenamento

\section{WINTER SEASON SOYBEAN SEED YIELD AND PHYSIOLOGICAL QUALITY}

\begin{abstract}
Soybean may be used as a relay crop in rotation systems. Such systems yield high physiological quality seeds and determine a short storage period until the next crop. The effect of plant density of soybean cultivars sown in the winter season in Selvíria, SP, Brazil, was studied in relation to plant height, first legume height, seed yield and seed physiological quality. Trials were set up in a randomized block design $(n=4)$, comprising seven soybean cultivars (IAC-16, IAC-Foscarin 31, FT-2, IAC-17, IAC-8, Doko and FT-Cristalina) sown at three plant densities (300,000/ha, 400,000/ha and 500,000/ha). There was a sharp decrease in the number of days to maturity (R8 stage) mainly for the late cultivars. The photoperiod in the winter season is short, mainly between flowering and maturation. The IAC-8 cultivar presented less sensitivity to the photoperiod, spending the same number of days to maturity (R8 stage) as for the late cultivars, and the had the best agronomic characteristics for the winter season. It is not recommended to store seeds under controlled conditions, mainly when germination values are close to the acceptable value $(80 \%)$.
\end{abstract}

Key words: plant population, cultivars, first legume height, seed storage

\section{INTRODUÇÃO}

A maior parte da cultura da soja (Glycine max) no Brasil é semeada no mês de novembro, por possuir as características fisiológicas de uma planta termo e fotossensível e, também, às condições agroclimáticas do país. Atualmente, novas alternativas de época de semeadura têm sido pesquisadas, em função da necessidade de rotação com outras culturas e a possibilidade de uma segunda "safra" em um mesmo ano agrícola, podendo proporcionar ao agricultor maior rentabilidade. Nesse contexto, nas áreas onde não ocorrem baixas temperaturas limitantes ao desenvolvimento da soja durante o outono/inverno, e onde há disponibilidade de água no solo (natural ou por irrigação) é possível seu cultivo na entressafra.

Contudo, o cultivo de soja em condições de dias curtos diminui o tempo para o início do florescimento, principalmente em cultivares considerados de ciclo tardio (Berlato, 1981; Rolim et al., 1982; Bergamaschi et al., 1977; Lazarini, 1995) que crescem menos, refletindo em menor altura da planta (Tragnago \& Bonetti, 1984; Board \& Settimi, 1986 e Lazarini, 1995), aliada a uma menor altura de inserção das primeiras vagens (Barni et al., 1978 e Vernetti, 1983), afetando negativamente a produtividade e aumentando as perdas de produção na cultura. 
Entretanto, tem-se obtido sucesso com o cultivo da soja fora da época convencional quando da utilização de cultivares de ciclo médio a tardio. O mesmo não se tem verificado com cultivares de ciclo precoce e semiprecoce (Villela et al., 1979; Miyasaka et al., 1970; Athayde et al., 1984; Lazarini, 1995).

Os bons resultados quanto à produção obtidos em cultivos fora da época convencional são observados também na qualidade fisiológica das sementes de soja produzidas (Rolim et al., 1982; Marcos Filho et al., 1984; Paolinelli et al., 1984; Tragnago \& Bonetti, 1984; França Neto et al., 1985a; 1985b; Nakagawa et al., 1986 e Medina, 1994).

O presente trabalho de pesquisa teve por objetivo avaliar o comportamento de sete cultivares de soja quanto ao porte e altura de inserção da primeira vagem, assim como quanto à produção e qualidade fisiológica das sementes, quando semeadas no período de inverno na região de Selvíria-MS.

\section{MATERIAL E MÉTODOS}

O experimento foi realizado na Fazenda de Ensino e Pesquisa da Faculdade de Engenharia Campus de llha Solteira - UNESP, localizada no município de Selvíra-MS, a $20^{\circ} 22^{\prime}$ LS. O clima predominante na região é classificado como do tipo $\mathrm{Aw}$, com temperatura e precipitação média anual de $23,6^{\circ} \mathrm{C}$ e $1330 \mathrm{~mm}$, respectivamente. $O$ solo da área experimental foi classificado como Latossolo Vermelho Escuro argiloso distrófico, apresentando as seguintes características químicas: M.O. $=25 \mathrm{~g} \mathrm{dm}^{-3}, \mathrm{pH}\left(\mathrm{CaCl}_{2}\right)=5,6, \mathrm{P}$ resina $=$ $25 \mathrm{mg} \mathrm{dm}^{-3}, \mathrm{H}+\mathrm{Al}, \mathrm{K}, \mathrm{Ca}, \mathrm{Mg}, \mathrm{SB}$ e CTC $=23,3,28,14$, 45 e $68 \mathrm{mmol}_{\mathrm{c}} \mathrm{dm}^{-3}$, respectivamente, e $\mathrm{V}=66 \%$.

$O$ delineamento experimental utilizado foi em blocos casualizados, com 4 repetições, dispostos em esquema fatorial $7 \times 3$. Os tratamentos constaram de sete cultivares (IAC-16, IAC-Foscarin 31, FT-2, IAC-17, IAC8, Doko e FT-Cristalina) e três densidades de plantas $\left(300,400\right.$ e 500 mil plantas ha $\left.^{-1}\right)$. Na Tabela 1 estão contidas as principais características dos cultivares fornecidos pelas instituições detentoras dos materiais. A soja foi semeada em 24/06/94, com a emergência ocorrendo em 02/07/94. Durante a condução do experimento a média da temperatura máxima foi de $34,8^{\circ} \mathrm{C}$ e, da temperatura mínima de $18,7^{\circ} \mathrm{C}$, com uma precipitação total até o último dia do mês de agosto de $39 \mathrm{~mm}$ e, desse momento até o último dia do mês de novembro de $460 \mathrm{~mm}$.

Para a obtenção das populações, colocou-se no sulco de semeadura um número de sementes superior ao de plantas desejadas por metro linear, levando-se em consideração uma germinação de $80 \%$, acrescido de uma margem de segurança de $20 \%$. Após 20 dias aproximadamente da emergência, realizou-se o desbaste manual, deixando-se o número de plantas desejado por área em cada parcela.
As parcelas constituíram-se de seis linhas de 6,0 metros de comprimento, espaçadas em $0,50 \mathrm{~cm}$, onde considerou-se como área útil as quatro linhas centrais. Dentro de cada bloco, o espaçamento entre parcelas foi de $1,0 \mathrm{~m}$, e entre eles também foi deixado um espaçamento para manuseio de tubulações de irrigação no valor de 1,0 m.

A adubação básica foi calculada mediante a análise do solo, segundo recomendação de Raij et al. (1985), constituindo-se a mesma de $300 \mathrm{~kg} \mathrm{ha}^{-1} \mathrm{da}$ fórmula 04-30-10. Foi adicionado no sulco de semeadura $40 \mathrm{~kg} \mathrm{ha}^{-1}$ do produto FTE $\mathrm{Br} 12$, o qual apresenta a seguinte constituição: $9,2 \%$ de $Z n, 2,2 \%$ de $B, 0,8 \%$ de $\mathrm{Cu}, 0,1 \%$ de $\mathrm{Mo}, 3,7 \%$ de $\mathrm{Fe}$ e $3,4 \%$ de Mn. Antes da semeadura, as sementes foram inoculadas com Bradyrhizobium japonicum, na dosagem de $250 \mathrm{~g}$ de inoculante para cada $40 \mathrm{~kg}$ de sementes, por tratar-se de uma área já cultivada anteriormente com a cultura da soja. Também foi aplicado molibdênio via semente na dosagem de $4 \mathrm{~g} \mathrm{ha}^{-1}$ na forma de molibdato de sódio e ainda o fungicida Thiabendazole, na dosagem de $20 \mathrm{~g}$ de i.a./100 kg de semente.

Durante a condução do experimento, a cultura foi irrigada por aspersão por um sistema autopropelido. Utilizaram-se tensiômetros como indicadores do momento de irrigação, adotando a tensão de reposição de água no solo sempre que atingia $-0,033 \mathrm{MPa}$ até o início do estágio R7. Os demais tratos culturais (capinas, controle de pragas e doenças) foram realizados à medida em que eram necessários, tanto na forma preventiva como curativa.

Após a maturação (estágio R8 e vagens com coloração marrom) de cada cultivar, realizou-se manualmente a colheita das plantas pertencentes a área útil de cada parcela, submetendo-as à trilha mecânica para a obtenção das sementes. Estas foram pesadas e posteriormente determinado o teor de água pelo método da estufa, para cálculo da produção de sementes (com $13 \%$ de teor de água). Devido às diferenças de épocas de maturação que ocorreram entre os cultivares, realizou-se a colheita das parcelas assim que as mesmas atingiram a maturação, o que acarretou a não colheita de todas as parcelas em uma única vez.

Determinaram-se as seguintes variáveis: época de florescimento e maturação, número de dias após a emergência quando aproximadamente $50 \%$ das plantas encontravam-se no estádio $R_{1}$, e número de dias após a emergência até a maturação, estádio $R_{8}$, respectivamente, conforme descrito em Costa (1982); altura de inserção da primeira vagem, altura das plantas, massa de 100 sementes, e produtividade de sementes.

Após a colheita do experimento, as sementes já trilhadas, foram conduzidas até o Laboratório de Análises de Sementes da Faculdade de Engenharia - Campus de Ilha Solteira/UNESP, para análises: determinou-se a 
porcentagem de sementes deformadas da produção obtida de cada parcela, retirando-se duas amostra de 100 sementes, as quais foram separadas manualmente em sementes normais e deformadas (trincadas, picadas por percevejo, enrugadas, mal granadas, com manchas características de doenças).

Coletou-se uma amostra de sementes de cada parcela, que foram utilizadas para as análises laboratoriais. Nas amostras, foram determinadas a qualidade fisiológica das sementes, através do teste de germinação, baseando-se nas Regras para Análise de Sementes (Brasil, 1992), e de testes de vigor (primeira contagem, índice de velocidade de germinação, envelhecimento acelerado e condutividade elétrica) segundo Vieira \& Carvalho (1994).

Os testes de germinação, primeira contagem, velocidade de germinação, envelhecimento acelerado e condutividade elétrica, foram realizados imediatamente após a colheita de cada cultivar e novamente após seis meses de armazenamento. A realização destes testes aos seis meses após a colheita teve como objetivo a determinação da viabilidade das mesmas para a semeadura após esse período, em condições não controladas de armazenamento. Assim, este foi realizado em sala de laboratório sob temperatura média mínima de $22^{\circ} \mathrm{C}$ e média máxima de $28^{\circ} \mathrm{C}$ e UR $=60-80 \%$.

Foi considerado na análise estatística da qualidade de sementes, o fator "época" como sendo o tempo de armazenamento das sementes colhidas (0 e 6 meses após a colheita da cultura).

Os dados foram submetidos à análise de variância e utilizou-se o teste Tukey a $5 \%$ para comparação das médias. Os dados de sementes deformadas foram transformados em arco seno da raiz quadrada de $x / 100$.

\section{RESULTADOS E DISCUSÃO}

Quanto ao número de dias necessários para o florescimento (Tabela 1), apenas nos cultivares considerados de ciclo médio a tardio (IAC-8 e FTCristalina) houve redução no número de dias, quando comparado aos dados apresentados pelas instituições introdutoras dos materiais em semeadura de verão. Os cultivares precoces e semi-precoce, proporcionaram dados semelhantes.

Quanto ao número de dias necessários para a maturação (Tabela 1), novamente verifica-se a formação de dois grupos entre os cultivares, sendo um grupo precoce e outro tardio. Nesses grupos a cultivar IAC-17, considerado semi-precoce quanto ao florescimento, possui uma maturação em número de dias igual às precoces, possuindo um período bastante curto entre 0 florescimento e a sua maturação, e o cultivar IAC-8, considerado de ciclo médio, teve sua maturação semelhante às tardias, o que a caracteriza como uma das menos sensíveis à variação fotoperiódica, já que em semeadura de inverno, ocorre uma maior redução no ciclo dos cultivares tardios.

Em todos cultivares, ocorreu uma diminuição no ciclo quando comparadas aos relatados pelas instituições introdutoras dos materiais, em semeadura em época convencional (verão). Essa diminuição ocorreu principalmente no período entre o florescimento e a maturação, já que o tempo entre a germinação e o florescimento foi bem semelhante aos relatados pelas instituições.

Houve influência dos cultivares em todas as variáveis, (Tabela 2) da densidade na altura de inserção da $1^{\text {a }}$ vagem, na massa de 100 sementes e produção de sementes $e$, da interação cultivares $\times$ densidade na altura de inserção da $1^{\text {a }}$ vagem e produção de sementes.

Quanto ao parâmetro altura de inserção da $1^{\text {a }}$ vagem (Tabela 3 ), verifica-se que os cultivares IAC-17 (precoce), IAC-8 (médio), Doko e FT-Cristalina (tardias) manifestaram valores satisfatórios a colheita mecânica (>10 cm, Bonetti (1983)). Entretanto, analisando os dados de altura de plantas, constata-se que somente a IAC-8 é que apresentou altura acima do padrão (= $65 \mathrm{~cm}$, Bonetti (1983)), com resultados da Doko e FT-Cristalina bem próximas e, a IAC-17 bem aquém. Lazarini (1995) sugeriu a realização de alguma adaptação para a colheita de plantas menores que 65 $\mathrm{cm}$, porém com altura de inserção das primeiras vagens superior a $10 \mathrm{~cm}$, que é o desejável para colheita mecânica, já que as perdas devido as vagens não colhidas (por apresentarem pequena altura de inserção) não iriam ocorrer.

A altura de inserção das primeiras vagens compatível com a colheita mecânica (mesmo com altura de plantas reduzidas) foge à regra geral de que, aliado a um menor desenvolvimento das plantas em semeaduras tardias, tem-se menor altura de inserção das primeiras vagens, conforme relatos de Barni et al. (1978), Vernetti (1983) e Lazarini (1995). Já, o restante dos cultivares precoces (IAC-16, IAC-Foscarin 31 e FT2) proporcionaram valores bem abaixo do desejado, inclusive, também, quanto à altura de plantas. Resultados semelhantes, quanto à redução acentuada na altura de plantas de cultivares precoces e semiprecoces, quando semeados tardiamente, foram observados por Medina (1994) e Lazarini (1995), este último, com os cultivares IAC-17 e FT-Estrela. A redução na altura de plantas de soja, devido ao atraso na semeadura, foi comentado por Tragnago \& Bonetti (1984), Board \& Settimi (1986), e Lazarini (1995). O efeito da densidade de plantas foi constatado na altura da inserção da $1^{\text {a }}$ vagem (Tabela 3 ), ocorrendo interação entre os fatores estudados (Tabela 4). O aumento da densidade de semeadura aumentou a altura da inserção da $1^{\text {a }}$ vagem nos cultivares IAC-17, Doko e FT-Cristalina. 
Tabela 1 - Principais características dos cultivares fornecidos pelas instituições detentoras dos materiais e resultados de florescimento e maturação (dias após emergência) obtidos no experimento em semeadura de inverno.

\begin{tabular}{|c|c|c|c|c|c|c|c|}
\hline \multirow[b]{2}{*}{ Característica } & \multicolumn{7}{|c|}{ Cultivar } \\
\hline & $\begin{array}{c}\text { IAC- } \\
\text { Foscarin-31 }\end{array}$ & AC-16 & FT-2 & $\mathrm{AC}-17$ & AC-8 & $\begin{array}{c}\text { FT-b } \\
\text { Cristalina } \\
\end{array}$ & Doko \\
\hline & \multicolumn{7}{|c|}{ Resulta do da Instituição detentora do material } \\
\hline Altura da planta $(\mathrm{cm})$ & 92 & 85 & 72 & 75 & 110 & 82 & 90 \\
\hline Dias para florescimento & 35 & 35 & 40 & 35 & 50 & 55 & 55 \\
\hline Dias para maturação & 115 & 110 & 116 & 110 & 140 & 158 & 150 \\
\hline Ciclo & precoce & precoce & precoce & precoce & média & tardia & tardia \\
\hline \multirow[t]{2}{*}{ Peso de 100 grãos (gramas) } & 16,0 & 16,0 & 16,5 & 16,0 & 18,0 & 17,7 & 18,0 \\
\hline & \multicolumn{7}{|c|}{ Resultado obtido no experimento } \\
\hline Dias para florescimento & 38 & 38 & 38 & 43 & 47 & 47 & 47 \\
\hline Dias para maturação & 98 & 98 & 93 & 93 & 127 & 121 & 127 \\
\hline Ciclo & precoce & precoce & $\begin{array}{l}\text { super- } \\
\text { precoce }\end{array}$ & $\begin{array}{l}\text { super- } \\
\text { precoce }\end{array}$ & $\begin{array}{l}\text { semi- } \\
\text { precoce }\end{array}$ & $\begin{array}{l}\text { semi- } \\
\text { precoce }\end{array}$ & $\begin{array}{c}\text { semi- } \\
\text { precoce }\end{array}$ \\
\hline
\end{tabular}

Tabela 2 - Valores de F para as variáveis altura de inserção da primeira vagem, altura da planta, massa de 100 sementes e produtividade de sementes de cultivares de soja em função da densidade de plantas.

\begin{tabular}{|c|c|c|c|c|}
\hline Causa da variação & $\begin{array}{c}\text { Altura de inserção da } \\
1^{\text {a }} \text { vagem }\end{array}$ & Altura da planta & $\begin{array}{c}\text { Massa de } 100 \\
\text { semente }\end{array}$ & $\begin{array}{l}\text { Prod utividade de } \\
\text { semente }\end{array}$ \\
\hline & \multicolumn{4}{|c|}{ - } \\
\hline Cultivar & $151,73^{* *}$ & $306,45^{\star *}$ & $64,24^{* *}$ & $35,88^{\star *}$ \\
\hline Densidade & $18,05^{\star \star}$ & $2,34 \mathrm{~ns}$ & $3,41^{*}$ & $4,72^{*}$ \\
\hline \multirow[t]{2}{*}{ Cul. * Dens. } & $2,97^{* *}$ & $1,02 \mathrm{~ns}$ & $1,17 \mathrm{~ns}$ & $2,23^{*}$ \\
\hline & 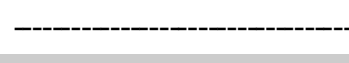 & 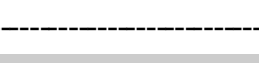 & /.(\%) - ----- & 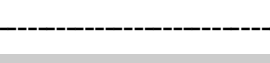 \\
\hline Cultivar & 14,04 & 7,94 & 5,69 & 20,10 \\
\hline Densidade & 12,51 & 10,82 & 6,99 & 18,08 \\
\hline
\end{tabular}

**, ${ }^{*}$ e ns, significativo a $1 \%$ e $5 \%$ e, não significativo, respectivamente pelo teste de Turkey.

Tabela 3 - Características de produção e produtividade de sementes dos cultivares e densidade utilizadas no experimento ${ }^{1}$.

\begin{tabular}{|c|c|c|c|c|}
\hline Tratame nto & Altura da $1^{\circ}$ vagem & Altura da planta & Massa de 100 sementes & $\begin{array}{l}\text { Prod utividade de } \\
\text { sementes }\end{array}$ \\
\hline Cultivar & --_-_-_--- Cr & --------------------- & $g$ & $\mathrm{~kg} \mathrm{ha}^{-1}$ \\
\hline IAC-16 & $6,9 d$ & $36,6 \mathrm{c}$ & $16,6 \mathrm{c}$ & $2051 b$ \\
\hline IAC-Foscarin 31 & $5,9 d$ & $27,3 \mathrm{~d}$ & $23,1 \mathrm{a}$ & $1261 \mathrm{c}$ \\
\hline $\mathrm{F}-2$ & $7,6 \mathrm{~d}$ & $29,6 \mathrm{~d}$ & $19,7 \mathrm{~b}$ & $1088 \mathrm{c}$ \\
\hline $\mathrm{IAC}-17$ & $10,6 \mathrm{c}$ & $36,7 \mathrm{c}$ & $18,7 \mathrm{~b}$ & $2060 \mathrm{~b}$ \\
\hline $\mathrm{IAC}-8$ & $20,0 \mathrm{a}$ & $78,2 \mathrm{a}$ & 24,6 a & $2614 a b$ \\
\hline Doko & $20,3 a$ & $55,0 \mathrm{~b}$ & $19,9 \mathrm{~b}$ & $2531 \mathrm{~b}$ \\
\hline FT-Cristalina & $17,0 \mathrm{~b}$ & $57,0 \mathrm{~b}$ & $19,5 \mathrm{~b}$ & 3112 a \\
\hline \multicolumn{5}{|l|}{ Densidade } \\
\hline 300.000 plantas ha-1 & $11,4 \mathrm{~b}$ & $44,2 \mathrm{a}$ & $20,1 \mathrm{a}$ & 1967 b \\
\hline 400.000 plantas ha $^{-1}$ & $12,5 b$ & 46,2 a & 20,9 a & $2066 \mathrm{ab}$ \\
\hline 500.000 plantas ha-1 & 13,9 a & 47,0 a & $20,0 \mathrm{a}$ & $2273 a$ \\
\hline
\end{tabular}

${ }^{1}$ Médias seguidas pela mesma letra não diferem pelo teste de Tukey a $5 \%$.

Scientia Agricola, v.59, n.1, p.79-86, jan./mar. 2002 
Tabela 4 - Altura de inserção da primeira vagem e produtividade de sementes de cultivares de soja em função da densidade de plantas ${ }^{1}$.

\begin{tabular}{|c|c|c|c|c|c|c|}
\hline & \multicolumn{6}{|c|}{ - } \\
\hline & 300 & 400 & 500 & 300 & 400 & 500 \\
\hline & \multicolumn{3}{|c|}{ Altura de $1^{\circ}$ vagem } & \multicolumn{3}{|c|}{ Produtividade de semente } \\
\hline Cultivar & ------------ & $---\mathrm{cm}--\cdot-$ & 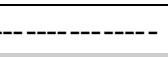 & - & $-\mathrm{kg} \mathrm{ha}^{-1}-$. & - \\
\hline IAC-16 & $6,3 \mathrm{cA}$ & $7,1 \mathrm{bA}$ & $5,7 \mathrm{cA}$ & 1920 bcA & $1967 \mathrm{abA}$ & $2267 \mathrm{abA}$ \\
\hline AC-Foscarin 31 & $5,1 \mathrm{cA}$ & $6,9 \mathrm{bA}$ & $7,3 \mathrm{cA}$ & $1145 \mathrm{dA}$ & $1295 \mathrm{cA}$ & $1345 \mathrm{baA}$ \\
\hline FT-2 & $6,3 \mathrm{cA}$ & $8,0 \mathrm{bA}$ & $8,6 \mathrm{cA}$ & $900 \mathrm{dA}$ & $1123 \mathrm{cA}$ & $1152 \mathrm{cA}$ \\
\hline IAC-17 & $8,5 \mathrm{cB}$ & 10,4 bAB & $12,8 \mathrm{bA}$ & $1722 \mathrm{cdB}$ & 1577 bcB & 2880 aA \\
\hline IAC-8 & $21,0 \mathrm{aA}$ & $17,5 \mathrm{aA}$ & $21,4 \mathrm{aA}$ & $2870 a b A$ & $2332 a b A$ & 2640 aA \\
\hline Doko & $18,3 \mathrm{abB}$ & $20,0 \mathrm{aAB}$ & $22,7 \mathrm{aA}$ & 2667 abcA & $2415 a b A$ & 2512 aA \\
\hline FT-C ristalina & 14,3 bB & $17,8 \mathrm{aAB}$ & 18,9 aA & 3152 aA & 3065 aA & 3120 aA \\
\hline
\end{tabular}

(1)Médias seguidas de mesma letra, minúscula na vertical e maiúscula na horizontal, não diferem pelo teste de Tukey a $5 \%$.

O efeito da densidade de plantas sobre a altura de inserção das primeiras vagens e sobre a altura de plantas foi comentado por Arf (1985), na qual em baixas populações as plantas tendem a desenvolver menos, apresentar mais ramificações, maior diâmetro do caule, maior número de vagens por planta e menor altura de inserção das primeira vagens. No presente trabalho, esse efeito não se manifestou em todos os cultivares, provavelmente por apresentarem características diferentes necessitando assim, um maior número de tratamentos de densidades com populações superiores e inferiores as estudadas.

Quanto à massa de 100 sementes (Tabela 3), houve apenas efeito de cultivares, tendo nos cultivares IAC-Foscarin 31 e IAC-8 os seus maiores valores e na IAC-16 os menores (característica desses cultivares). 0 efeito de densidade verificado no teste $F$ (Tabela 2), não se manifestou na análise de comparação de médias.

Os dados de produção de sementes permitem constatar (Tabelas 3 e 4), para essa época de cultivo, maiores resultados quando se utiliza cultivares de ciclo médio a tardio, em relação às precoces como também observado por Athayde at al. (1984), Villela et al. (1979), Lazarini (1995) e Miyasaka et al. (1970) em semeaduras tardias. O efeito da densidade de plantas também foi significativo, sendo a maior densidade mais produtiva que a menor, o que também foi observado por Nakagawa et al. (1983) utilizando os cultivares Paraná, Santa Rosa e UFU-1, e Nakagawa et al. (1986) com o cultivar IACFoscarin 31 , semeada no mês de dezembro. Devido a um menor desenvolvimento das plantas, pode-se utilizar um maior número de plantas por área, objetivando uma maior produção, desde que se tenha meio eficiente de fornecimento de água, pois trata-se de uma época de total deficiência hídrica, ou seja, haverá também uma maior competição entre as plantas pela água, sendo a necessidade de irrigação um fator primordial.

Analisando o desdobramento da interação para produção de sementes (Tabela 4) verifica-se efeito significativo apenas para o cultivar IAC-17. Um fator importante a evidenciar é a tendência do aumento da produção aliado ao aumento da densidade ocorrer somente nos cultivares precoces. Nos cultivares de ciclo médio e tardio, essa tendência ocorreu de forma inversa principalmente entre 300 e 400 mil plantas ha ${ }^{-1}$, porém nada significativo, a não ser para o cultivar IAC-17. Esse efeito "positivo" da densidade em cultivares precoces e "negativo" nas de ciclo médio e tardio, pode estar aliado ao desenvolvimento desses cultivares nessa época, como já comentado.

$\mathrm{Na}$ Tabela 5, encontram-se os valores de $\mathrm{F}$ da análise estatística das variáveis avaliadas para qualidade fisiológica de sementes, obtidos aos 0 e 6 meses após a colheita, exceção feita à percentagem de sementes deformadas, que só foi avaliada imediatamente após a colheita. O efeito de cultivares e épocas foi altamente significativo em todos as variáveis avaliadas, e significativo a $5 \%$ para efeito das densidades.

Os valores referentes à germinação estão sempre abaixo do mínimo necessário para a utilização desse lote como semente no Estado do Mato Grosso do Sul (80\%) (Embrapa, 1993), principalmente seis meses após a colheita (Tabela 6). Estes resultados divergem de Miyasaka et al. (1970) e Rolim et al. (1982), que obtiveram sementes de boa qualidade em semeaduras de inverno. Em relação aos cultivares utilizadas, verificase que a IAC-16, FT-2, IAC-17 e IAC-8 foram as que apresentaram os melhores resultados mesmo após seis meses de armazenamento. Este comportamento diferencial entre cultivares foi relatado por Carraro et al. (1982) e Vieira et al. (1983). O único cultivar que estatisticamente não variou a germinação durante o armazenamento foi a IAC-17.

Os dados obtidos quanto ao envelhecimento acelerado revelaram que os cultivares FT-2 e IAC-8 manifestaram o mesmo vigor seis meses após a primeira avaliação. Entretanto, os cultivares IAC-16, IAC-Foscarin 31, IAC-17, Doko e FT-Cristalina decaíram muito quanto à porcentagem de sementes envelhecidas que germinaram, mostrando ser cultivares que durante 0 
Tabela 5 - Valores de F para as variáveis germinação, envelhecimento acelerado, índice de velocidade de emergência (I.V.E.), condutividade elétrica e sementes deformadas de cultivares de soja em função da densidade de plantas logo após a colheita e aos seis meses após a colheita.

\begin{tabular}{|c|c|c|c|c|c|}
\hline Causa da Variação & Germinação & $\begin{array}{c}\text { Enve lhecime nto } \\
\text { acelerado }^{1}\end{array}$ & I.V.E. & $\begin{array}{c}\text { Condutividade } \\
\text { elétrica }\end{array}$ & $\begin{array}{c}\text { Semente } \\
{\text { Deformad }{ }^{1}}^{2}\end{array}$ \\
\hline Cultivar (C) & $10,95^{\star *}$ & $14,10^{* *}$ & $11,77^{* *}$ & $28,38^{* *}$ & $9,85^{\star *}$ \\
\hline Densidade (D) & $6,64^{\star *}$ & $3,86^{\star}$ & $6,11^{\star *}$ & $3,90^{*}$ & $0,65 n s$ \\
\hline Época (E) & $80,47^{* *}$ & $223,81^{* *}$ & $79,94^{* *}$ & $18,71^{* *}$ & ---------_---_-----' \\
\hline$C^{*} D$ & 0,85ns & $1,49 n s$ & $0,84 \mathrm{~ns}$ & 1,09ns & $0,62 \mathrm{~ns}$ \\
\hline$C * E$ & $1,42 \mathrm{~ns}$ & $24,04^{\star \star}$ & $1,44 \mathrm{~ns}$ & $1,02 \mathrm{~ns}$ & 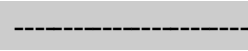 \\
\hline$D^{*} E$ & $0,48 n s$ & $1,27 \mathrm{~ns}$ & $0,5 \mathrm{lns}$ & $2,47 n s$ & 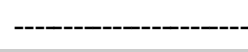 \\
\hline \multirow[t]{2}{*}{$C * D * E$} & $1,09 \mathrm{~ns}$ & $0,89 \mathrm{~ns}$ & $1,05 \mathrm{~ns}$ & $1,83 \mathrm{~ns}$ & 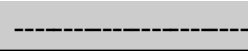 \\
\hline & & & C.V. (\%) & & \\
\hline Cultivar & 22,15 & 21,46 & 22,09 & 15,67 & 23,10 \\
\hline Densidade & 17,41 & 19,45 & 17,47 & 16,95 & 29,93 \\
\hline Época & 15,59 & 22,68 & 15,55 & 12,53 & ------------------- \\
\hline
\end{tabular}

**, * e ns, significativo a $1 \%$ e $5 \%$ e, não significativo, respectivamente.

${ }^{1}$ Valores obtidos com os dados transformados em arco seno da raiz quadrada de x/100.

Tabela 6 - Germinação, envelhecimento acelerado, índice de velocidade de emergência (I.V.E.), condutividade elétrica e sementes deformadas de cultivares de soja em função da densidade de plantas logo após a colheita e aos seis meses após a colheita ${ }^{1}$.

\begin{tabular}{|c|c|c|c|c|c|c|c|c|c|}
\hline & \multicolumn{2}{|c|}{ Germinação } & \multicolumn{2}{|c|}{$\begin{array}{c}\text { Envelhecimento } \\
\text { Acelerado }\end{array}$} & \multicolumn{2}{|c|}{ I.V.E. } & \multicolumn{2}{|c|}{ Condutividade elétrica } & \multirow[t]{2}{*}{$\begin{array}{c}\text { Semente } \\
\text { Deformada }\end{array}$} \\
\hline & 0 mês & 6 meses & 0 mês & 6 meses & 0 mês & 6 meses & 0 mês & 6 meses & \\
\hline Cultivar & \multicolumn{4}{|c|}{--_--- } & & & \multicolumn{2}{|c|}{-------- $\mu \mathrm{mho} \mathrm{g}^{-1}$-_------ } & $\%$ \\
\hline IAC-16 & 79,6 aA & $64,6 \mathrm{aB}$ & 68,8 aA & $3,6 \mathrm{~dB}$ & 7,9 aA & $6,4 \mathrm{aB}$ & $113,5 \mathrm{cB}$ & 128,2 bcA & $5,3 \mathrm{c}$ \\
\hline IAC-Foscarin 31 & $61,1 \mathrm{bA}$ & $47,5 \mathrm{bcB}$ & $41,2 \mathrm{cA}$ & $5,1 \mathrm{~dB}$ & $6,1 \mathrm{bA}$ & $4,7 \mathrm{bcB}$ & 159,4 aA & $159,3 \mathrm{aA}$ & $21,1 \mathrm{a}$ \\
\hline FT-2 & $79,1 \mathrm{aA}$ & $69,8 \mathrm{aB}$ & 54,6 bcA & 48,1 aA & $7,9 \mathrm{aA}$ & $7,0 \mathrm{aB}$ & $85, \mathrm{IdB}$ & $98,4 \mathrm{dA}$ & $12,1 \mathrm{~b}$ \\
\hline IAC-17 & $72,5 \mathrm{abA}$ & 65,3 aA & $62,6 \mathrm{abA}$ & $15,9 \mathrm{cB}$ & $7,2 \mathrm{abA}$ & $6,5 \mathrm{aA}$ & $111,1 \mathrm{cB}$ & $128,7 \mathrm{bcA}$ & $10,2 \mathrm{bc}$ \\
\hline IAC-8 & $69,0 \mathrm{abA}$ & $57,8 \mathrm{abB}$ & $41,0 \mathrm{cA}$ & $32,8 \mathrm{bA}$ & $6,9 \mathrm{abA}$ & $5,7 a b B$ & $111,3 \mathrm{cB}$ & $124,0 \mathrm{bcA}$ & $15,6 a b$ \\
\hline Doko & $63,5 \mathrm{bA}$ & $46,3 \mathrm{bcB}$ & $48,0 \mathrm{bcA}$ & $29,4 \mathrm{bcB}$ & $6,3 \mathrm{bA}$ & $4,6 \mathrm{bcB}$ & $115,4 \mathrm{bcA}$ & $118,7 \mathrm{cdA}$ & $15,8 a b$ \\
\hline FT-Cristalina & $61,8 \mathrm{bA}$ & $40,6 \mathrm{cB}$ & $46,3 \mathrm{bcA}$ & $15,7 \mathrm{cB}$ & $6,1 \mathrm{bA}$ & $4,0 \mathrm{cB}$ & $135,0 \mathrm{bA}$ & $146,1 \mathrm{abA}$ & $12,6 b$ \\
\hline \multicolumn{10}{|l|}{ Densidade } \\
\hline 300.000 planta ha-1 & \multicolumn{2}{|c|}{$60,0 \mathrm{~b}$} & \multicolumn{2}{|c|}{$32,7 \mathrm{~b}$} & \multicolumn{2}{|c|}{$6,0 \mathrm{~b}$} & \multicolumn{2}{|c|}{$123,9 a b$} & ----------- \\
\hline 400.000 planta $^{h^{-1}}$ & \multicolumn{2}{|c|}{$61,1 \mathrm{~b}$} & \multicolumn{2}{|c|}{$33,1 a b$} & \multicolumn{2}{|c|}{$6,1 \mathrm{~b}$} & \multicolumn{2}{|c|}{129,4 a } & -------_- \\
\hline 500.000 planta ha-1 & \multicolumn{2}{|c|}{$67,0 \mathrm{a}$} & \multicolumn{2}{|c|}{$38,3 a$} & \multicolumn{2}{|c|}{$6,6 \mathrm{a}$} & \multicolumn{2}{|c|}{$118,3 b$} & --------- \\
\hline
\end{tabular}

(1)Médias seguidas pela mesma letra, minúscula na vertical e maiúscula na horizontal, não diferem pelo teste de Tukey a $5 \%$.

armazenamento não podem sofrer adversidades do ambiente (alta temperatura e alta umidade) que provocam diminuição significativa na qualidade. Nesse teste verificou-se que os cultivares IAC-8 e, principalmente, a FT-2 são as mais resistentes, mesmo após ao armazenamento de 6 meses. Quanto ao I.V.E. verifica-se a mesma tendência dos cultivares observada na germinação, já que são dois parâmetros que estão diretamente relacionados, pois se obtiveram os maiores valores para os cultivares que apresentaram maior porcentagem de germinação.

Os dados de condutividade elétrica também apresentaram a mesma tendência constatada na germinação, porém de maneira inversa, como era esperado. Assim, quanto maior o valor observado para a condutividade elétrica, menor foi a porcentagem de germinação. Um fato observado através dos dados da Tabela 6 , foi que os cultivares que tiveram sementes com as mais baixas porcentagens de germinação (IACFoscarin 31, Doko e FT-Cristalina) não apresentaram diferenças significativas quanto à condutividade elétrica entre 0 e 6 meses após a colheita, o que comprova a baixa qualidade das mesmas desde o início dos testes (0 mês).

Com relação à porcentagem de sementes deformadas (Tabela 6), verifica-se que se obteve com a IAC-16, sementes de melhor qualidade visual. Após essa avaliação, essas sementes deformadas foram descartadas para a condução dos testes de qualidade fisiológica. Apesar disso, o cultivar IAC-16 que 
apresentou melhor qualidade visual de semente, também proporcionou maior porcentagem de germinação. Nem sempre essa relação foi manifestada, provavelmente devido a algumas sementes que visualmente tinham boa aparência, poderiam estar contaminadas por algum patógeno ou poderiam ter sofrido algum dano latente durante sua fase de formação ou principalmente durante a colheita.

Para todas as variáveis a densidade de 500 mil plantas ha ${ }^{-1}$ proporcionou sementes de melhor qualidade (Tabela 6). Nakagawa et al. (1986) também obtiveram diferenças na qualidade de sementes em diferentes densidades de semeadura. Em outro trabalho, no entanto, os mesmos autores (Nakagawa et al., 1983) obtiveram dados totalmente diferentes em dois experimentos, quanto ao efeito da densidade e, também, quanto à interação cultivares $\mathrm{x}$ densidades de semeadura.

\section{CONCLUSÕES}

O ciclo da soja foi reduzido no cultivo de inverno, principalmente nos cultivares considerados tardios; o fotoperíodo no cultivo de inverno reduz principalmente o período entre o florescimento e a maturação; o cultivar IAC-8 foi a menos sensível ao fotoperíodo, possuindo maturação em época semelhante aos cultivares tardios, e apresentou as melhores características agronômicas para o cultivo no período de inverno; é aconselhável o aumento de densidade de semeadura quando do uso de cultivares precoces em cultivos de inverno; não é aconselhável armazenar sementes em condições ambientes, onde prevalecem temperaturas e umidades elevadas, principalmente com valores de germinação próximo ao limite inferior desejável (80\%); a produção de sementes em cultivo de inverno é maior quando se utiliza cultivares de ciclo médio a tardio; o aumento da densidade de semeadura proporciona sementes com maior germinação e mais vigorosas.

\section{REFERÊNCIAS BIBLIOGRÁFICAS}

ARF, O. Comportamento do amendoim (Arachis hypogaea L.) e da soja (Glycine max (L.) Merrill) com diferentes densidades de plantas em área de reforma de canavial. Jaboticabal, 1985. 65p. Dissertação (Mestrado) Faculdade de Ciências Agrárias e Veterinárias, Jaboticabal, Universidade Estadual Paulista "Júlio de Mesquita Filho".

ATHAYDE, M.L.F.; RODRIGUES, R.; ARF, O. Comportamento de cultivares de soja em semeadura tardia na região de Jaboticabal (SP). In: SEMINÁRIO NACIONAL DE PESQUISA DE SOJA, 3., Campinas, 1984. Anais. Londrina: EMBRAPA, CNPSo, 1984. p.441-448.

BARNI, N.A.; BERGAMASCHI, H.; GOMES, J.E.S. Época de semeadura e cultivares de soja para o Rio Grande do Sul. IPAGRO Informa, v.21, p.67-70, 1978.

BERGAMASCHI, H.; BERLATO, M.A.; WESTPHALEM, S.L. Épocas de semeadura de soja no Rio Grande do Sul: avaliação e interpretação dos ensaios ecológicos de soja. IPAGRO Informa, v.18, p.7-14, 1977.
BERLATO, M.A. Exigências bioclimáticas e zoneamento agroclimático. In: MIYASAKA, S.; MEDINA, J.C. (Ed.) A soja no Brasil. Campinas: ITAL, 1981. p.175-184.

BOARD, J.E.; SETTIMI, R. Photoperiod effect before and after flowering on branch development in determinate soybean. Agronomy Journal, v.78, p.905-1002, 1986.

BONETTI, L.P. Cultivares e seu melhoramento. In: VERNETTI, F.J. (Ed.) Soja: genética e melhoramento. Campinas: Fundação Cargill, 1983. p.741-794.

BRASIL. Ministério da Agricultura e Reforma Agrária. Regras para análise de sementes. Brasília: SNAD; DNDV; CLAV, 1992. 365p.

CARRARO, I.M.; SEDIYAMA, T.; SILVA, R.F.; REIS, M.S.; THIEBAUT, J.T.L. Influência do retardamento da colheita sobre a qualidade das sementes de soja (Glycine max (L.) Merrill). In: SEMINÁRIO NACIONAL DE PESQUISA DE SOJA, 2., Brasília, 1981. Anais. Londrina: EMBRAPA, CNPSo, 1982. v.1, p.61-75.

COSTA, J.A. Caraterísticas dos estádios de desenvolvimento da soja. Campinas: Fundação Cargill, 1982. 30p.

EMPRESA BRASILEIRA DE PESQUISA AGROPECUÁRIA. Serviço de Produção de Sementes Básicas. Padrões estaduais de sementes. Brasília: EMBRAPA; SPI, 1993. p.35-37.

FRANÇA NETO, J.B.; COSTA, N.P.; HENNING, A.A.; CABRAL, N.T.; MENDES, M.C. Efeito da época de semeadura sobre a qualidade da semente de soja produzida no Mato Grosso. Londrina: EMBRAPA, CNPSo, 1985a. p.428-433. (Documentos, 15).

FRANÇA NETO, J.B.; HENNING, A.A.; COSTA, N.P.; ZUFFO, N.L. Efeito da época de semeadura sobre a qualidade da semente de soja no Mato Grosso do Sul. Londrina: EMBRAPA, CNPSo, 1985b. p.434-439. (Documentos, 15).

LAZARINI, E. Avaliação das características agronômicas e análises nutricionais de genótipos de soja semeadas em diferentes épocas, em Jaboticabal-SP. Jaboticabal, 1995. 197p. Tese (Doutorado) - Faculdade de Ciências Agrárias e Veterinárias, Universidade Estadual Paulista "Júlio de Mesquita Filho".

MARCOS FILHO, J.; MIRANDA, M.A.C.; KOMATSU, Y.H. Época de semeadura e qualidade fisiológica de sementes de soja. In: SEMINÁRIO NACIONAL DE PESQUISA DE SOJA, 3., Campinas, 1984. Anais. Londrina: EMBRAPA, CNPSo, 1984, p.132.

MEDINA, P.F. Produção de sementes de cultivares precoces de soja, em diferentes épocas e locais do Estado de São Paulo. Piracicaba, 1994. 173p. Tese (Doutorado) - Escola Superior de Agricultura, "Luiz de Queiroz", Universidade de São Paulo.

MIYASAKA, S.G.G.; KIIHL, R.A.S.; LOYADINI, L.A.C.; DEMATTÊ, J.D. Variedades de soja indiferentes ao fotoperiodismo e tolerantes a baixas temperaturas. Bragantia, v.29, p.169-173, 1970.

NAKAGAWA, J.; ROSOLEM, C.A.; MACHADO, J.R. Épocas de semeadura de soja: I. Efeito na produção de grãos e nos componentes de produção. Pesquisa Agropecuária Brasileira, v.l8, p.1187-1198, 1983.

NAKAGAWA, J.; MACHADO, J.R.; ROSOLEM, C.A. Efeito da densidade de plantas e da época de semeadura na produção e qualidade de sementes de soja. Revista Brasileira de Sementes, v.8, p.99-112, 1986.

PAOLINELLI, G.P.; TANAKA, M.A.S.; REZENDE, A.M. Influência da época de semeadura sobre a qualidade fisiológica e sanitária de sementes de soja. Revista Brasileira de Sementes, v.6, p.39-50, 1984.

RAIJ, B. van; SILVA, N.M.; BATAGLIA, O.C.; QUAGGIO, J.A.; HIROCE, R.; CANTARELLA, H.; BELLINAZZI JR., R.; DECHEN, A.R.; TRANI, P.E. Recomendações de adubação e calagem para o Estado de São Paulo. Campinas: Instituto Agronômico; SAAESP, 1985. 107p. 
ROLIM, R.B.; MONTEIRO, P.M.F.O.; COSTA, A.V.; BUENO, J.G.; STEINFORFF, A.P. Estudo do comportamento da soja (Glycine max (L.) Merrill), na entressafra (dias curtos) no estado de Goiás. In: SEMINÁRIO NACIONAL DE PESQUISA DE SOJA, 2., Brasília, 1981. Anais. Londrina: EMBRAPA, CNPSo, 1982. p.425-440.

TRAGNAGO, J.L.; BONETTI, L.P. Diferentes épocas de semeadura no rendimento e outras características de alguns cultivares de soja no Rio Grande do Sul. In: SEMINÁRIO NACIONAL DE PESQUISA DE SOJA, 3., Campinas, 1984. Anais. Londrina: EMBRAPA, CNPSo, 1984. p.57-69.

VERNETTI, F.J. Genética da soja; características qualitativas. In: VERNETTI, F.J. (Ed.) Soja: genética e melhoramento. Campinas: Fundação Cargill, 1983. p.93-124.

VIEIRA, R.D.; CARVALHO, N.M. Testes de vigor em sementes. Jaboticabal: FUNEP, 1994. 164p.
VIEIRA, R.D.; SEDIYAMA, T.; SILVA, R.F.; SEDIYAMA, C.S.; THIEBAUT, J.T.L. Avaliação da qualidade fisiológica de sementes de quatorze cultivares de soja (Glycine max (L.) Merrill). Ceres, v.30, p.408-418, 1983.

VILLELA, L.; SPEHAR, C.R.; SOUZA, P.I.M.; VIEIRA, R.D. Comportamento de cultivares de soja em época seca (inverno) no cerrado do Distrito Federal. In: SEMINÁRIO NACIONAL DE PESQUISA DE SOJA, 1., Londrina, 1978. Anais. Londrina: EMBRAPA, CNPSo, 1979. v.1, p.357-363.

Recebido em 03.10.00 